\title{
SUSTAINABLE DESIGN AND THE DESIGN CURRICULUM
}

\author{
Dr Tania HUMPHRIES-SMITH \\ Bournemouth University \\ School of Design, Engineering \& Computing \\ Poole House, Talbot Campus \\ Fern Barrow \\ Poole, Dorset \\ BH12 5BB, UK
}

Email - thumphri@bournemouth.ac.uk

\begin{abstract}
Biographical Notes:
Dr Tania Humphries-Smith is an Associate Dean at Bournemouth University. Her teaching areas are Engineering and Product Design. She was in professional practice as a Product Designer before entering Academia. She is also a Member of the Institution of Engineering Designers and Member of Council, as well as a Chartered Engineer. Her research activities are centred on sustainable product design, specifically, the socialcultural aspects of sustainable design. She is currently researching the psychology of product attachment and how product life spans can be increased. She has published papers in design education since 1998.
\end{abstract}

\section{ABSTRACT}

This paper reports on an initial study that begins the process of considering how design education should deal with the issue of sustainable design specifically in the context of the education of graduate designers in the fields of product, design engineering and interior design. Consideration is given to the development of the design curriculum and the design process. Further, a number of questions related to shaping the future of design and engineering education are also explored. The question this research seeks to address is whether sustainability, or more specifically sustainable design, should or can be an integral part of engineering/product design programmes or whether it should/or can be developed as a separate design discipline, perhaps as a postgraduate extension to the designer's core skills set? The research also discusses the difference between, ecodesign and sustainable design and the implications of the understanding of this difference for design education.

Keywords: sustainability, eco-design, environmental design, curriculum, design education, design process, sustainable design; sustainable development 


\section{INTRODUCTION}

\subsection{Context}

We are currently operating within the 'Decade of Education for Sustainable Development' as defined by UNESCO as being 2005-2015. HM Government of UK has determined a sustainable development strategy that states 'Our strategy for sustainable development aims to enable people throughout the world to satisfy their needs without compromising the quality of life for future generations.' (HM Government, 2005, p6). This in turn has driven an action plan for education and skills in the UK which states 'We need to look at sustainable development as a whole - how to use our resources without wasting them; how to teach and learn about sustainable development; how to generate the skills, knowledge and understanding to allow us to fulfil our duty as global citizens.'(Clark, 2005, p3). In line with this, Higher Education Funding Council for England (HEFCE) via the consultation paper 'Sustainable development in higher education' (HEFCE, 2005) have clearly indicated that a sustainable focus should be adopted throughout higher education in the UK, however, sustainability has particular and more far reaching implications in the design/engineering context.

The importance for design and engineering is further emphasized by Lord Sainsbury "Everyone, especially engineers, should have sustainability literacy as a basic skill", 21st February 2003. And the Royal Academy of Engineering -

Sustainable development is the process of moving human activities to a pattern that can be sustained in perpetuity. It is an approach to environmental and development issues that seeks to reconcile human needs with the capacity of the planet to cope with the consequences of human activities.” (2005, p7).

Additionally, the new standards of Professional Engineering Competence (UK-SPEC) (Engineering Council UK, 2005, p11) Competence E3, requires engineers to "undertake engineering activities in a way that contributes to sustainable development.” Thus, in some way all engineering and design courses are required to address the broad issue of sustainability.

\subsection{Literature Review}

Before discussing the wider literature it is important to clarify the meanings of various terms, namely, eco-design and sustainable design. The idea of eco-design has been around for more than a decade, for example the ECODESIGN Information Platform (ECODESIGN Team, 1996) has been in operation since 1996. In her essay setting out the history of ecological design Madge (1997) suggests that eco-design had just been replaced by sustainable design as she was writing, eco-design having replaced green design as the term of the late 1980s. She asserts that

The transition from "green" to "eco" to "sustainable" in the design field represents

a steady broadening of scope in theory and practice... (p45).

Madge quotes Dewberry \& Goggin (1994, p7-8) in her definition of sustainable design as

The concept of sustainable design, however, is much more complex and moves the interface of design outwards toward societal conditions, development and ethics.....

and involves

a general shift from physiological to psychological needs. (p49) 
The idea of psychological needs being significant with respect to sustainable design will be returned to later in this discussion.

Clearly the integration of eco-design issues and associated techniques (as for example specified in ISO14062 BSI, 2002) has implications for the whole design and development process. Verhulst and Baelus (2006), and Charon (2005) among others, discuss various aspects of how eco-design affects the design and development process. Charon reports on a case study at Herman Miller Inc of the development of a new product using a new protocol that required placing a high value on responsibility to the environment. It is reported that the additional constraints cannot be met by conventional design solutions and require demand creative alternatives. However, the protocol focuses on an environmental rating tool for products, use of environmentally friendly materials and disassembly guidelines which are essentially elements of eco-design.

Verhulst and Baelus discuss an approach to incorporating eco-design methodology into the existing new product development process. They base their integrated method on the 1997 eco-design methodology of Brezet et al, part of the Ecodesign Manual that they claim is still one of the most complete eco-design manuals, which presents a roadmap of eco-design. They comment that the most significant changes to the development process due to eco-design occur in the early stages. Brezet et al (1997) emphasise the importance of a needs analysis, the first heading in their Ecodesign Checklist. Their needs analysis requires consideration of how a product might fulfil social needs effectively and efficiently which of course leads immediately to the question of whether the product should be designed at all, or replaced by a system or service design. Sherwin \& Bhamra (2001) also argue that eco-design must be incorporated early in the design process. Bhamra et al (2001), after Brezet, present the notion of there being 4 levels of ecodesign challenge and suggest that research and practice had moved to level 2 , incorporating eco-design in the design process, by 2001. They also suggest a new research area emerging related to level 2, the concept of replacing products by services. This originates from a consideration of the actual consumer needs, that is, a needs analysis, which may result in a product not being required at all.

Fletcher \& Goggin (2001) use a case study approach based on clothes washing to investigate the environmental implications of consumer (human) behaviours. Fletcher $\&$ Goggin (2001, p25) focus on needs analysis as "a focus on the design of products, services or systems cannot continue without consideration of people's needs.” They also pick up on the idea of needing to "connect with people's aspirations and expectations." This idea will be discussed again later in this paper.

Edwards (2005) clearly defines eco-design as concerning the environmental impacts of products during their life cycle, but sees sustainable design related to the social aspects of manufacture. This is seen to include the humanization of design which includes consideration of factors such as the conditions under which the products are manufactured. Sustainable design necessitates consideration of business values, social responsibility and ethics within product design. Edwards also considers this definition of sustainable design to include consideration of how our consumptive lifestyles can be addressed, via concepts such as dematerialization and product service systems. As Edwards notes, the tools for evaluating the social performance, such as the Global Reporting Index (GRI) and SA8000, deal with company performance not product 
design and development. Larssaether (2005) discusses the morality of products in the context of Corporate Social Responsibility (CSR). He suggests that the current CSR agenda has not changed practice and that it needs to be broadened to include moral product/service systems. Further, Tischner et al (2000) clearly sees product design (being economic, functional, aesthetic, safety aspects) as a subset of ecodesign (which adds environmental aspects) which in turn is a subset of sustainable design (which adds social \& ethical aspects) being that which is required for a sustainable existence.

Fuad-luke (2004) in the Eco-design Handbook defines a comprehensive range of ecodesign strategies but while providing a wide range of products examples and referring to a robust tool kit, does not actually provide any real 'how-to' information for the designer.

The Royal Academy of Engineering's (RAEng) 12 Guiding Principles (2005) focus on sustainable design, acknowledging that successful sustainable development requires three dimensions, the techno-centric, the eco-centric and the socio-centric, to be brought together. Interestingly, the terms "technocentric" and "ecocentric" were used as early as 1976 by O’Riordan to define opposing outlooks, the former being the use of science and technology to manage the environment and the latter looking for morally and ecologically sound alternatives to large scale industry. The RAEng's three dimensions are defined as:

- $\quad$ Eco-centric - The ability of the planet to sustain us - by providing material and energy resources. Eg:

- Sustainable Development: Concepts, models, indicators and assessment.

- Climate change: Warming and cooling factors, the carbon cycle.

- Resource depletion: Renewable, non-renewable, resource management.

- $\quad$ Energy demand: Supply chain, conservation, efficiency.

- Alternative energy technologies: Types, potential, density, costs.

- Techno-Centric - Techno-economic systems that include the skills that engineers must continue to deploy and the economic system within which they are deployed. Eg:

- Environmental impact: Life cycle assessment tools

- Material selection: Material selection tools

- Design for waste minimisation tools

- Sustainable design assessment tools

- Socio-centric - Human expectations and aspirations - the needs of human beings to live worthwhile lives. Eg:

- Cradle to cradle approach

- Dematerialization - products replaced by services

- $\quad$ Ethical supply chains -

- Expansion of product life span

Interestingly, the 12 Guiding Principles, themselves, do not fully address all aspects of the 3 dimensions, for example, principle 9. - Adopt a holistic, 'cradle to grave' approach (p8) - is not holistic and, as discussed later, the socio-centric dimension can be considered to require a 'cradle to cradle' approach. 
Approaches to teaching are also discussed in chapter 5 of the 12 Guiding Principles, and a four step process is suggested as a way to develop the required capability to answer ECUK requirements. This four step approach consists of:

1. using an essay to determine awareness of the concept of sustainable development;

2. undertaking an analysis of the life-cycle of a product

3. reviewing all teaching modules to incorporate aspects such as sourcing of materials and waste minimization;

4. bringing the elements above together through project work.

The authors' main criticism of this four step approach is that it does not address all three of the dimensions of sustainable design that the Royal Academy of Engineering themselves present in chapter 1 . of the 12 Guiding Principles. This approach really only addresses the techno and eco-centric dimensions and even then at a fairly surface level of depth.

Case studies are presented alongside the Guiding Principles. Of particular interest, is one on mobile phones from a study by Nokia. This Nokia study was driven by European legislation in the form of the Integrated Product Policy (IPP) and the directives on Waste Electrical and Electronic Equipment (WEEE) and the Restriction on the Use of Certain Hazardous Substances in Electrical and Electronic Equipment (RoHS). Clearly, legislation has an increasing impact in the work of designers and engineers in sustainability and eco-design and thus, should be considered in the education of designers and engineers.

For the 3 dimensions to be fully addressed, a significant shift in consumer behaviour and patterns of consumption is required, along with a change in the nature of solutions developed to address sustainable design problems. It is increasingly important for product designers and engineers to consider all aspects of sustainable design when developing solutions to design problems. Yet one element is excluded from eco-design , namely the socio-centric dimension.

So, exactly what is meant by the socio-centric dimension? In the context of sustainable product design it can be argued that "the methods through which we currently address sustainability are not as sustainable as we might like to think” (Chapman, 2005, p170). The rationale behind this argument is that the methods and techniques currently in use appear to go straight to the third, and least preferable, of the 'three Rs' of sustainable design - "REDUCE - REUSE - RECYCLE”, when focus should be placed on reduce and reuse first. McDonough and Braungart (2002) are also critical of ecological waste by recycling, pointing out that this is still a one-way process from 'cradle to grave' rather than a cycle of reuse such as their notion of 'cradle to cradle'. The subtitle of the work of McDonough and Braungart (2002), 'remaking the way we make things', is telling. Their notion is that in nature there is no such thing as 'waste', material is simply a biological or technical nutrient. Applying their notion means rethinking design and manufacture completely. They give example such as the fabrics they chose to use in the Airbus 380. These fabrics are edible, that is, a biological nutrient. The concept of 'cradle to cradle' requires a new approach to business because it is no longer a single transaction of consumption but becomes an ongoing contract. Inevitably, the nature of this direction means that questions about the replaceable nature of products and hence, 
the effect on the business model are thus raised adding a whole new dimension to be considered.

It is now recognised that the focus needs to move from the techno and eco-centric dimensions, to include the socio-centric dimension. This includes a move to reusing and increasing product life span. Cooper (2005, p63) identifies that -

A deeper exploration of consumer values and attitudes is needed to understand how people might reduce their desire to acquire more possessions and, instead, increase their attachment to those that they currently own.

Others, such as Brezet (1997) and Fletcher \& Goggin (2001) question the need for a product in the first place, this is often referred to as 'dematerialization'. Manzini \& Jegou (2003) explore the socio-centric aspects of sustainable design. They conclude that there needs to be a focus on living strategies rather than employing more technology in the traditional functions of living. They take the approach of investigating the user social behaviour and then considering the technical system role, leading to solutions which are less, product focused, and more system focused and which result in less control by the individual but rather by a system that takes environmental considerations into account. Manzini has suggested a virtuous cycle in which society would be reorientated to sustainability by a series of micro-changes led by consumers which he identifies as the emerging of radical social innovation (UNEP DTIE, 2004). Thus, there is a clear link with these notions regarding the socio-centric dimension and the definition of sustainable design discussed earlier which requires the fulfilment of peoples needs but in an eco-efficient way which considers ethical supply chains as well as ‘cradle to cradle' considerations.

Otto (2007) offers her thoughts on sustainable design via The Design Council website. She refers to the 3 pillars of sustainable design, social, environmental and economic and comments that seen as 3 balls, "The trick is to keep them working together in a single, smooth process....we often don’t juggle too well.” Simon \& Dixon (2007) focus on life extension and support the view that the socio-centric dimension is key to sustainable design, although they refer to eco-design, commenting that

designers often ignore the social and cultural aspects. Ecodesign especially when practised by engineering designers, is taken as a technical problem.

Again, case studies are provided with those of the Aeron Chair by Herman Miller inc., the Kodak Disposal Camera and the Reverse Vending Machine being of most interest here. All focus almost exclusively on eco-design principles and techniques such as design for disassembly and design for recycling. The disposable camera is interesting for it apparently supports a 'throwaway' culture but the claim is made that they are in more 'use' than non-disposable cameras due to re-manufacture. While the claim is made that the Aeron chair is so comfortable that people want to take it with them and that maintenance in situ is facilitated both features thus increasing the length of time of use before disposal.

Desmet \& Hekkert (2007) pick up on from the notion of increasing the length of time of use before disposal, by increasing attachment to products so they are not disposed of so quickly, in other words, extending the product life span (Cooper, 2005). Desmet \& Hekkert (2007) consider how products are experienced and claim to have developed a framework of product experience, based on theories from psychology, which includes instrumental interaction, non-instrumental and non-physical interaction. They use core 
affect theory to organize product experience into 3 levels - aesthetic pleasure; attribution of meaning and emotional response. Their concepts of attribution of meaning and emotional response have important implications for the development, or otherwise, of attachment to a product.

Schifferstein et al (2004) have also investigated product attachment. They have used methods taken from psychology research to inform their use of a mail questionnaire to 200 members of a consumer household panel, 12 of whom were later interviewed. The responses were subjected to principle components analysis (PCA) and regression analysis which resulted in the suggestion that products show a decrease in attachment after first year but that products over 20 years old had highest levels of attachment. Ornaments had higher attachments than the other three categories (clocks, cars and lamps). 7 factors were identified from PCA - the memories of persons; events and places; the extent to which the product supports the persons identity; the products utility; the life vision it symbolizes; the enjoyment it activates; its market value and its reliability. They concluded that

If a designer wants people to become attached to his/her product, the present study suggests that s/he should facilitate ways to form associations between the product and people, places or events (memories), or s/he should design a product that evokes enjoyment. (Schifferstein et al, 2004, p330)

\subsection{Problem Statement}

As indicated earlier a clear direction is being given from the Government, HEFCE and professional engineering bodies that sustainable design must become part of the education of all students in design and engineering courses. The scale and complexity of sustainable design, particularly as opposed to eco-design is large, as indicated in the previous discussion. Then, of course, there is the little matter of the increasing legislative requirements that are impacting all designers and engineers. However, as also evidenced by the previous discussion none of these concepts are new, a comprehensive definition of sustainable design has existed for nearly a decade. Papanek back in 1971 identified that design could become a harmful profession for the environment. So how has sustainable design been integrated or considered in the design curriculum?

There is a small amount of historical data on the integration of sustainability into the design curriculum. Ramirez (2006) reports on a study based on Australian education of industrial designers in which he had responses from 26 academics and all 12 universities that offer industrial design or product design in Australia. He concludes that

This paper demonstrates that aspects of environmentally sensitive design are currently being incorporated in most Australian industrial design degree programs, albeit to a minor extent. The higher challenge is to go beyond "ecodesign" into the greater sphere of "sustainable design" of which ecodesign is a subset...(p199)

Ramirez also refers to some UK and USA based studies which are worth considering here. The UK studies discussed were conducted by the Government Sustainable Development Education Panel (GSDEP) which concluded its work in 2003 with the publication of the Government's Sustainable Education Development Strategy. However, the work of this panel is almost exclusively confined to school and further education rather than Higher Education for which the report refers to the HEFCE 
document, discussed in the introduction. Nguyen \& Pudlowski (1997) conducted a study into engineering courses but this is now rather historical and based again in Australia and specifically in Monash University. Interestingly it is reported as being suggested that a separate 4 year environmental engineering course might be a solution to the difficulties of integrating sustainability into the engineering design curriculum. Ramirez (2006, p192) also refers to a 2001 USA based study in which only 12 per cent of industrial design educators reported ecodesign to be integrated into their curricula.

Ramirez (2007) extended his 2006 study to cover the world, including the UK, however, it is not clear how many responses were obtained from the 61 UK institutions Ramirez identified as having design courses. Ramirez only sought the views of academics and reports that

72 percent believe that their ID graduates demonstrate a reasonable understanding of sustainable design issues and strategies. In spite of these, many of the respondents highlighted hardships in integrating sustainability into their industrial design curricula, particularly when the current programs of study are already "full”...(p1)

Ramirez although he did not directly seek a definition of sustainable design also identified that

Most participants seemed to interpret sustainable design as being identical with ecological design or green design....and usually not covering the aspects of promoting an equitable society.(p3)

As Ramirez in both studies has only sought the views of academics it is impossible to triangulate the data and ascertain a rich picture of what learning in actually taking place and what learning needs to take place for a graduate designer entering the design profession.

Thus, for UK design education at degree level and above the questions still arise:

- Do we all know what we mean by sustainable design?

- To what extent is sustainable design being integrated into the design curriculum in the UK?

- Should we be educating all designers to deal with sustainability issues or would it be better to educate specialists in sustainable design?

What is reported on here is an initial or pilot study that begins investigation of these questions.

\section{METHODOLOGY}

The methodology was determined in the light of the study being an initial investigation and in order to obtain a rich picture of the extent and needs of education with respect to sustainable design. The research was undertaken in two stages. Firstly an evaluation was made of the number, nature and content of existing undergraduate design and engineering courses on offer at UK Higher Education Institutions. Secondly, a survey was undertaken to determine the current views about sustainable design, of those involved with the higher education of designers and engineers, including those being educated, that is, undergraduates.

The evaluation was undertaken using data from the University Central Admissions Service (UCAS) website for entry to courses in academic year 2008/2009 which contains information on the range of undergraduate courses available. Data was also 
obtained from the websites of Higher Education Institutions (HEIs) to obtain specific course content information. It was determined to limit the study solely to undergraduate courses because there is no requirement for designers and engineers in the UK to undertake post-graduate study before they practice and it only a small percentage of graduates do go on to post-graduate study. Therefore, they would not be representative of the sector as a whole.

The survey of people involved in the higher education of designers and engineers was undertaken using questionnaires. The views of the following groups of people involved in higher education of designers and engineers were sought:

- $\quad$ academics in design and engineering departments with IED accredited courses of UK HEIs;

- students on existing engineering/product design courses at Bournemouth University;

- $\quad$ employers of placement students and graduates from these courses.

The following questions were used in the questionnaires to academics:

1. To what extent are your design/engineering students aware of sustainable design issues?

2. To what extent do your design/engineering students apply sustainable design tools/techniques?

3. To what extent do you think all designers/engineers should be aware of sustainable issues?

4. To what extent do you think all designers/engineers should be able to apply sustainable design techniques?

5. Would you consider providing a course that produces a graduate who is a specialist sustainable designer? Please give reasons for your answer.

6. What do you consider sustainable design to be?

Questions 5 \& 6 were free answers, whereas questions 1-4 required a choice of not at all; a little; working knowledge or high level. The exact wording of the questions were modified to make them appropriate to academic, employer or students, for example, question 1. became: 'To what extent are your designers/engineers aware of sustainable design issues?' for employers and 'To what extent are you aware of sustainable design issues?' for students.

The wording and order of the questions were considered and a conscious decision was made to put the question relating to the definition of sustainable design last. The reason for this was to obtain the instinctive reactions of the respondents to the questions, before encouraging them to actively consider their own definition of sustainable design. It was felt this would lead to a more accurate assessment of the current 'state of the art' with respect to the place of sustainable design in the curriculum.

A small scale study was undertaken based on a specific sample of people whose experiences were known to be relevant. The academics were all involved with courses accredited by the Institution of Engineering Designers (IED), thus it can be reasonably presumed they hold a common view as to the requirements of the design and engineering professions. The IED is the only UK professional institution to accredit product design courses. Unlike Australia where there are only 12 universities that run industrial design courses (Ramirez 2006) in the UK there are in excess of 60 HEIs 
running over 300 courses which incorporate product design in the title (data UCAS course database accessed $3^{\text {rd }}$ July 2008). Therefore, it is impossible to obtain any real common ground as to what a product design course should contain, hence, it was decided to limit this study to known and accredited courses that have a common understanding of product design. The academics should all be expected to know about the professional requirements for engineers and designers, however, it is accepted that some respondent bias be inevitable as those that responded may be more passionate about sustainability than the non-respondents.

The students were all from the BA/BSc Product Design course (accredited by the IED) run at Bournemouth University (BU), this group was chosen as the detail of the curricula, and thus, content and nature of sustainable design, were known to the researcher. In terms of the content of sustainable design on this course it is largely considered through materials and manufacture units and also through project units, indeed it could be considered to be consistent with the majority of the courses in the findings of Ramirez (2007). Interestingly, as Ramirez (2007) notes, BU offers a BSc Sustainable Design course, however, this has yet to run as it has not recruited sufficient numbers.

The employers were all employers of graduates and placement students from courses at Bournemouth University (BA/BSc Product Design; BSc Computer Aided Product Design; BSc Design Engineering, BA Interior Design). Thus enabling it to be reasonably presumed that a, professionally focused, and shared view, of the requirements of graduate designers and engineers would be held by all respondents. The advantage of this limitation is that it removes discussions of a more general nature about the content of design and engineering curricula which would detract from the specific focus on sustainable design and its position in relation to the design and engineering curricula. It is accepted that the study is limited but it was only intended as an initial study and to gain rich data that could be triangulated to obtain a fuller picture of the state of sustainable design education in the UK, both in terms of extent and need.

\section{RESULTS}

\subsection{Evaluation of existing HE provision}

All design and engineering courses with the words sustainable or sustainability in the title were investigated in more detail to ascertain the content of the curriculum. This included courses with titles such as BSc Sustainable Product Design, BSc Sustainable Design, BEng Sustainable Engineering, BA Product Design: Sustainable Design and BA Product Design Sustainable Futures. All these courses were on offer on the University Central Admissions Service (UCAS) website for entry in academic year 2008/09. It should be noted that this did not include construction, civil or environmental engineering courses as they are considered outside the scope of this investigation. Looking more closely at the content of these courses, in the context of the three dimensions of sustainability, it was found that at worst they include a couple of modules that deal with some of the tools associated with eco-design and specifically the technocentric dimension, for example, Life Cycle Analysis. At best modules are integrated throughout the course building from overall sustainable development issues and related technologies through environmental impact assessment, environmental law, regulation and management, to include energy efficiencies and clean technologies, however, still with an emphasis on the techno and eco-centric dimensions. Very typically modules 
form part of a framework of design and engineering courses which share common units/modules with sustainable design being one pathway.

A random sample of 10 engineering and design courses was also investigated using data from HEIs websites for any apparent sustainable content. From the data available 9 do raise the awareness of sustainable development and related design issues in a general sense and for some (3), it would appear, in at least as much depth as those courses with sustainable design in the title but which include only a couple of modules. This finding is supported by the more rigorous study by Ramirez (2007) where only 11 percent said their curriculum didn't cover any sustainable design, albeit it is not possible to identify exact statistics for the UK and that the majority of design courses have 17.5 percent or less sustainability content.

Of course, most design and engineering courses are already heavily 'packed' with content and, therefore, it is difficult to see how yet more material could be fitted into cover the depth and breadth of sustainable design. Certainly, some elements, mainly those of eco-design, fall naturally into units/modules already commonly taught on engineering and design courses, for example, Life Cycle Analysis; consideration of renewable materials and energy consumption. Again this is supported by the Ramirez (2007) study.

The existence of these courses within design education raises a number of questions. How for example, does BSc Sustainable Product Design differ from BSc Product Design? What message is being sent? Does the BSc Product Design programme not consider sustainability? And what is lost in terms of content on the BSc Sustainable Product Design to make space for sustainable design content?

\subsection{Views of Academics}

16 institutions (covering approximately 60 courses) were sent questionnaires, 13 replies were received, all from different institutions and all from academics in institutions with IED accredited courses none of which included sustain** in the title. It should be noted that in most institutions where a number of design courses are accredited it is normal for one academic to be the IED contact and it was this academic to whom the questionnaire was addressed.

Table 1 Results of Questionnaire - Academics

\begin{tabular}{|c|c|c|c|c|}
\hline Question & Not at all & A little & $\begin{array}{c}\text { Working } \\
\text { knowledge }\end{array}$ & High level \\
\hline Qu 1 & & & 8 & 5 \\
\hline Qu 2 & & 3 & & 1 \\
\hline Qu 3 & & & 10 & 3 \\
\hline Qu 4 & & & 7 & 6 \\
\hline
\end{tabular}

Question 5. - Five responses were outright 'no', four of these due to lack of market (one of these had had a programme in the past and that programme had now closed) and one response was that it should be embedded in Product Design or Design Engineering programmes. Two responses were yes in the future when there is likely to be demand. Six responses were 'yes', one only at masters level, another indicated that many 
students go on to study this subject area at masters level, the three remaining all identified a likely future demand due to changes in legislation.

Question 6. - The responses to this question, while demonstrating a range of depth, tended to have a common theme which is perhaps most concisely captured by the following two definitions: "The strategic use of design to meet consumer need without compromising the environment" and "Satisfying consumer needs whilst minimising the environmental impact”. More limited views spoke of use of renewable resources, use of life cycle analysis and focus on manufacture, use and disposal.

\subsection{Views of current Students}

Responses were received from students on BA/BSc Product Design (PD) (levels C \& H) - a total of 44.

Table 2 Results of Questionnaire - Students

\begin{tabular}{|c|c|c|c|c|}
\hline Question & Not at all & A little & $\begin{array}{c}\text { Working } \\
\text { knowledge }\end{array}$ & High level \\
\hline Qu 1 & 2 PD & 23 PD & 15 PD & 3 PD \\
\hline Qu 2 & 3 PD & 33 PD & 7 PD & \\
\hline Qu 3 & & & 15 PD & 29 PD \\
\hline Qu 4 & & 2 PD & 19 PD & 22 PD \\
\hline
\end{tabular}

Question 5. - Views were very split in response to this question, approximately half said 'no' in many cases because it was a 'boring subject'. The other half were positive but ranged from 'only as part of design course' to 'yes, complete course'. While many mentioned the importance of sustainable design in the future, a few mentioned that they had studied sustainability at school and that was sufficient.

Question 6. - generally the responses were either of a shallow or a very broad nature 'design that considers the environment' and 'design that uses sustainable materials' were common themes. A few level $\mathrm{H}$ responses from Product Design students were more considered such as

Design for the now without impacting on the future: a true sustainable design will be holistic and have completely closed loops in terms of materials and energy.

\subsection{Views of Employers}

70 questionnaires were sent out from which 19 replies were received, all from employers of either placement and/or graduate students, as listed on the placement company database, from the Design programmes of the School of Design, Engineering and Computing, Bournemouth University.

Table 3 Results of Questionnaire - Employers

\begin{tabular}{|c|c|c|c|c|}
\hline Question & Not at all & A little & $\begin{array}{c}\text { Working } \\
\text { knowledge }\end{array}$ & High level \\
\hline Qu 1 & 1 & 12 & 5 & 1 \\
\hline Qu 2 & 3 & 11 & 5 & \\
\hline Qu 3 & & & 8 & 11 \\
\hline Qu 4 & & & 8 & 11 \\
\hline
\end{tabular}

Question 5. - 5 replied 'yes' but that they would have to be an all round designer as well. 6 replied 'no' largely due to being too small to employ a specialist. 8 replied 'yes' 
they felt it would be essential in the future, with one feeling it might give them 'a competitive edge'.

Question 6. - most responses spoke about materials being either recyclable or renewable with some referring to the carbon footprint of materials. More rounded responses are typified by the following example:

minimize impact on environment through long life cycles, parts re-placeability, classic aesthetics and re-cyclability.

Indeed, the concept of timeless or classic design with respect to aesthetics was mentioned by several respondents. The most wide ranging response defined sustainable design as 'the designing of physical objects to comply with principles of economic/social sustainability'. Only two responses mentioned the fulfilment of legislative requirements.

\subsection{Analysis of Results}

The response to the closed questions (1-4) is interesting in that academics clearly consider their courses already address sustainable issues and provide a working knowledge of the tools/techniques, this concurs with the Ramirez studies (2006 \& 2007). Employers and students meanwhile do not consider they have such a high level of knowledge, nor that they have a 'working knowledge' of the tools and techniques. This apparent gap in perception between academics and their students and employers of their graduates needs further exploration and is not something that was explored in previous studies. It might suggest for example, that academics are not making the coverage of sustainable design explicit in their teaching; that academics are not actually covering as much as they think they are; that students are not absorbing the material that is covered or that there is a mismatch between what students and academics think is sustainable design.

There is a higher level of agreement, however, regarding the need for them to have a higher level of knowledge of the issues and of the tools/techniques, although here employers and students think it should be higher than academics. This may in part be related to the fact they have generally not got such a 'sophisticated' understanding of what sustainable design encompasses and, therefore, believe it to be relatively 'easy' to integrate into their existing education.

In response to the open questions none of the respondents used the term eco-design, although many referred directly and indirectly to environmental design or design for the environment. All respondents had some common concept of what sustainable design is, however, the definition varied in depth and breadth considerably. Generally, the academics had the most refined definitions, albeit, most of the respondents are referring to eco-design and not sustainable design. This has echoes in the findings of Ramirez (2007) who notes that

One respondent commented that "most design faculty members are not qualified to speak of sustainability: it is a complex issue driven by culture, economics and political forces.” (p4)

Thus, a very commonly held view among students and employers alike is that sustainable design should/can be an integral part of an education of a designer. All groups of respondents surveyed tended to see sustainable design as an issue for the future and not for now. Again this concurs with Ramirez study (2007) who notes that 
half see integration of sustainability in the curriculum occurring in 1-5 years and a quarter 6-10 years. Interestingly, several employers mention aesthetics as being important in the context of sustainable design, a concept which clearly links with the socio-centric dimension of sustainability but which was not mentioned by any academics or students.

\section{CONCLUSIONS \& RECOMMENDATIONS}

There is a general good level of awareness of eco-design issues and to some extent the tools and techniques associated with them, such as life cycle analysis. However, the wider issues covered by sustainable design are much less widely perceived and even less understood. This, it would appear, leads to the commonly held view that it should and can be part of a designers/engineers function/education. Additionally, the notion that sustainable design was something for the future was a common response which also suggests a lack of awareness of the speed with which legislative requirements are moving if nothing else.

In terms of the current state of design and engineering higher education with respect to sustainability, it would appear reasonable to say that the majority of courses have some element of sustainability as part of their curriculum whether this is made explicit in the title or otherwise. However, it would appear that courses which explicitly incorporate 'sustainable' into the title vary considerably. Courses with titles such as BSc Sustainable Product Design have, at best, incorporated eco-design principles into the design and development process in the way that Verhulst and Baelus report and at worst it would appear that in some cases this simply takes the form of one or two units related to eco-design being 'added on to' the curriculum.

However, if true sustainable design, as discussed previously in this paper, is to be considered rather than eco-design, it is rather more difficult to perceive how this could easily be incorporated into the existing education or functions of product designers or design engineers without detrimentally affecting other knowledge and skill areas. Therefore, it is suggested that there is a potential opportunity for the introduction to education and industry of specialist sustainable designers, initially this might be better at Post-graduate rather than Under-graduate level. Thus, allowing the 'traditional' skills of an engineer or designer to be developed and then to be modified and complemented by the additional and extended skills set required of a sustainable product designer/engineer, thus fulfilling the need for all round designers expressed by employers.

This would and should not preclude a general awareness of sustainable development issues being introduced into the curriculum of all design and engineering courses, as prescribed by HEFCE, Professional Institutions and the Engineering Council UK, which should, in any case, be a natural extension of the tertiary education curriculum. This should include some briefing as to the current legislative requirements regarding sustainability such that all designers and engineers are aware of their legal responsibilities but this does not necessarily mean they are best placed to ensure their designs meet those legislative requirements. 
This suggestion, of course, raises the question of knowledge and skills a specialist sustainable design might require and hence, what a course designed to educate a specialist sustainable designer might include?

As might be anticipated this paper has raised more questions than answers. Thus, the following areas are recommended for further investigation:

- A wider scale survey of design and engineering courses in the UK to confirm findings of this initial study about the sustainable design content of the courses.

- An investigation of the nature and extent of courses available at post-graduate level in sustainable design.

- A wider scale survey of employers of graduate designers and engineers to determine extent of sustainable design knowledge of their designers and perceived needs for sustainable design knowledge

- $\quad$ Determine a skills set for a specialist sustainable designer.

\section{ACKNOWLEDGEMENTS}

The author gratefully acknowledge the participation of employers of placement students and graduates from Design programmes in the School of DEC, Bournemouth University (BU), students on Product Design and Interior Design programmes, also at BU and academics from Institution of Engineering Designers (IED) accredited courses in this research.

\section{REFERENCES}

Bhamra, T., Evans, S.. van der Zwan, F., \& Cook, M. (2001) Moving from Eco-Products to EcoServices, Journal of Design Research. Available online: http://jdr.tudelft.nl/articles/issue2001.02/article3.html accessed 6th July 2008.

Brezet, H., Van Hemel, C. (1997) Ecodesign: a promising approach to sustainable production and consumption. United Nations Publication, UNEP, Paris.

British Standards. (2002) ISO/TR 14062:2002 Environmental management-Integrating environmental aspects into product design and development, British Standards Institute, UK.

Chapman, J. (2005) Emotionally Durable Design - objects, experience and empathy, Earthscan Publications Ltd, London, UK.

Charon, S. (2005) Product Development Processes: A Case Study in Sustainable Product Design, Proceedings of Towards Sustainable Product Design 10, Farnham, UK.

Clark, C. Rt Hon, MP. (2005) Sustainable development action plan for Education and Skills

Cooper, T. (2005) Slower Consumption - Reflections on Product Life Spans and the "Throwaway Society”, Journal of Industrial Ecology, 9(1-2), 51-67.

Desmet, P \& Hekkert, P. (2007) Framework of product experience. International Journal of Design, 1(1), 57-66.

Dewberry, E. \& Goggin, P. (1994) Ecodesign \& Beyond: Steps towards 'Sustainability', Open University and Nottingham Trent University, p7-8

ECODESIGN Team. (1996) ECODESIGN Information Platform, Institute for Engineering Design, Vienna University of Technology.

Edwards, S. (2005) Linking Sustainable Product Design with Corporate Social Responsibility: a Consideration of Frameworks and Measurement Tools, Proceedings of Towards Sustainable Product Design 10, Farnham, UK.

Engineering Council UK, (2005) Standards for Professional Engineering Competence (UKSPEC), ECUK, London, UK. 
Fletcher, K.T. \& Goggin, P.A. (2001) The Dominant Stances on Ecodesign: A Critique, Design Issues, 17(3), Massachusetts Institute of Technology, USA

Fuad-Luke, A. (1997) The Eco-Design Handbook, Thames \& Hudson, London, UK.

Government Sustainable Development Education Panel (GSDEP) (2003), Learning to Last - The Government's Sustainable Education Strategy for England, London.

HEFCE (2005) Sustainable development in higher education - consultation on a support strategy and action plan. Higher Education Funding Council for England, UK.

HM Government. (2005) Securing the future: delivering UK sustainable development strategy, Executive Summary

Larssaether, S. (2005) Moral products - the missing dimension of CSR? Proceedings of Towards Sustainable Product Design 10, Farnham, UK.

Madge, P. (1997) Ecological Design : A new critique, Design Issues, 13(2) p44-54

Manzini, E. \& Jegou, F. (2003) Sustainable Everyday, Scenarios of urban life, Edizione Ambiente, Milan, p231-234

McDonough, W \& Braungart, M. (2002) Cradle to Cradle - remaking the way we make things, North Point Press, New York, USA.

Nguyen, D. Q. \& Padlowski, Z. J. (1997) A comparative study of the perspectives of academics, students and industry on environmental education in engineering courses, Global Journal of Engineering Education, 1(3).

O’Riordan, T. (1976) Environmentalism, Pion Ltd, London.

Otto, B.K. (2007) Sustainability, Available: http://www.designcouncil.org.uk/en/AboutDesign/Business-Essentials/Sustainability [Accessed on 30th January 2008]

Papanek, V. J. (1971) Design for the Real World: human ecology and social change, Thames \& Hudson, London.

Ramirez, M. (2006) Sustainability in the education of industrial designers: the case for Australia, International Journal of Sustainability in Higher Education, 7(2), p189-202.

Ramirez, M. (2007). Sustainability Integration in Industrial Design Education: a world wide survey. Connected 2007 International Conference on Design Education, University of New South Wales.

Royal Academy of Engineering. (2005) Engineering for Sustainable Development: Guiding Principles, London, UK.

Scheifferstein, H.N. J., Mugge, R. and Hekkert, P. (2004) In McDonagh, D., Hekkert, P., Van Erp, J. and Gyi, D. eds. Design and Emotion: The Experience of Everyday Things, Taylor \& Francis, London, 317-321.

Sherwin, C. \& Bhamra, T. (2001) Early Ecodesign Integration: Experiences from a Single Case, Journal of Design Research, 1(2)

Simon, M. \& Dixon, A. (2007) In Otto, B.K. Sustainability, Available: http://www.designcouncil.org.uk/en/About-Design/Business-Essentials/Sustainability

[Accessed on 30th January 2008]

Tischner, U., Dietz, B., Masselter, S and Hirschl, B. (2000) How to do Ecodesign? A Guide for Environmentally and Economically Sound Design, Verlag Form, Frankfurt.

UNEP DTIE (2004) Meeting consumer demand for sustainable products - workshop, European Roundtable on Sustainable Consumption and Production, Bilbao, Spain, May 14th

Verhulst, E. \& Baelus, C. (2006) Implementation of an eco-efficiency approach into the methodology roadmap for integrated product development, Proceedings of 8th Engineering \& Product Design Education International Conference, Salzburg, p221-225. 